\title{
Neuroinflammation, Gut-Brain Axis and Depression
}

\author{
Alper Evrensel ${ }^{\natural}$, Barıs Önen Ünsalver², and Mehmet Emin Ceylan ${ }^{3}$ \\ ${ }^{1}$ Department of Psychiatry, Uskudar University, NP Brain Hospital, Istanbul, Turkey \\ ${ }^{2}$ Department of Medical Documentation and Secretariat, Vocational School of Health Services, Istanbul, Turkey \\ ${ }^{3}$ Department of Psychology and Philosophy, Uskudar University, Istanbul, Turkey
}

Psychiatric diseases are the manifestations that result from the individual's genetic structure, physiology, immunology and ways of coping with environmental stressors. The current psychiatric diagnostic systems do not include any systematic characterization in regard to neurobiological processes that reveal the clinical picture in individuals who got psychiatric diagnosis. It is obvious that further research in different areas is needed to understand the psychopathology. The problems in the functions of immune system and the correlation of neuroinflammatory processes with psychiatric disorders have been one of the main research topics of psychiatry in recent years and have contributed to our understanding of psychopathology. Recent advances in the fields of immunology and genetics as well as rapidly increasing knowledge on the effects of immunological processes on brain functions have drawn attention to the correlations between psychiatric disorders and immune system dysfunctions. There are still unfilled gaps in the biology, pathophysiology, and treatment of major depressive disorder, which is quite prevalent among the psychiatric disorders, can lead to significant disability, and frequently has a recurrent course. It appears that low-grade chronic neuroinflammation plays a key role in forming a basis for the interaction between psychological stress, impaired gut microbiota and major depressive disorder. In this review, the role of neuroinflammation in the etiopathogenesis of depression and the mechanism of action of the gut-brain axis that leads to this are discussed in the light of current studies.

Psychiatry Investig 2020;17(1):2-8

Key Words Microbiota, Gut-brain axis, Immune system, Depression, Neuroinflammation.

\section{INTRODUCTION}

Depression is one of the diseases with the highest mortality and morbidity rates in the world. ${ }^{1}$ Twenty out of every 100 people develop depression at some point in their lifetime. ${ }^{2}$ The rate of "years lived with disability" (10.3\%) is longer in depression than in all other diseases. ${ }^{3}$ Therefore, depression can be defined as a serious public health problem.

Given the etiopathogenesis of depression, it is seen that it is not only a brain disorder, but also has a close relationship with all body functions, especially the immune system and the endocrine system. ${ }^{4}$ In the etiology of depression, the heritability rate is between $48 \%$ and $37 \% .{ }^{5}$ However, the effect of environmental factors, especially diet and lifestyle changes, is indisputable in this etiology. ${ }^{6}$

\footnotetext{
Received: June 20, 2019 Accepted: August 9, 2019

$\triangle$ Correspondence: Alper Evrensel, MD

Department of Psychiatry, Uskudar University, NP Brain Hospital, Saray Mah. Ahmet Tevfik İleri Cad. No: 18 PK:34768 Umraniye, Istanbul, Turkey

Tel: +90 216 6330633, Fax: +90 216 6341250, E-mail: alperevrensel@gmail.com

(c) This is an Open Access article distributed under the terms of the Creative Commons Attribution Non-Commercial License (https://creativecommons.org/licenses/bync/4.0) which permits unrestricted non-commercial use, distribution, and reproduction in any medium, provided the original work is properly cited.
}

It is thought that modern lifestyle provides a basis for immune system dysfunction due to several causes, and that the leading cause is disruption of gut microbiota composition (dysbiosis), leading to neuroinflammation and depression.

\section{ETIOPATHOGENESIS OF MAJOR DEPRESSION}

In the 1950s, known as the golden age of psychopharmacology, the first psychopharmacological drugs were discovered and the synaptic functions have been started to be elucidated by means of spectrophotofluorometric analyses. ${ }^{8}$ During the next $2-3$ decades, depression was considered as a brain dysfunction. Problems with the hypothalamic-pituitary-adrenal (HPA) axis and the role of stress have been clarified over time. The neuroinflammation hypothesis has been advocated since 2000s. Evidence obtained in the last 10 years reveals a strong and bidirectional relationship between the gut and the brain. Gut microbiota has an essential role in the formation of both health problems and neuropsychiatric disorders. ${ }^{7}$ These four dimensions (neuronal/synaptic dysfunction, HPA axis, neuroinflammation and dysbiosis) should be analyzed in detail. 
Monoamine neurotransmitters (serotonin, dopamine and noradrenaline) play an important role in normal mood and anxiety/depression development. ${ }^{9}$ Although serotonin remains in the forefront, recent studies have also provided evidence regarding the function of other neurotransmitters in depression. The gamma-aminobutyric acid system has a hypoactive function, while the acetylcholine and glutamate system has a hyperactive function. ${ }^{10}$ The fact that antidepressants reduce the depressive symptoms by increasing the monoamine levels is an observation in favor of this hypothesis. However, the fact that the success rate of antidepressants is not $100 \%$ and they have a late onset of action suggests that other factors also play a role in the etiology of depression. ${ }^{11}$

One of the factors causing depression is the hyperactivity of the HPA axis. ${ }^{12,13}$ The HPA axis is activated as the response of the organism to stress. In patients with depression, there is an impairment in the negative feed-back mechanism that allows both hypercortisolemia and cortisol release to be halted. ${ }^{12}$ In addition to that, the glucocorticoid receptor sensitivity decreases in depression, and antidepressant treatments increase the amount of glucocorticoid receptors. ${ }^{13}$

According to the microbiota hypothesis, the gut-brain axis may be the missing link in the etiopathogenesis of neuropsychiatric diseases. ${ }^{7}$ The most important component of the gutbrain axis is the intestinal bacterial content, called microbiota. ${ }^{14}$ The microbiota begins to form from the first day of birth. ${ }^{7}$ In fact, according to some studies, the seeds of the gut microbiota are spread in the intrauterine period. ${ }^{15}$ Gut microbiota plays an essential role in functions such as maturation of the immune system, ${ }^{16}$ healthy functioning of the HPA axis and endocrine system, ${ }^{17}$ formation and maintenance of the bloodbrain barrier, ${ }^{18}$ neurogenesis, ${ }^{19}$ and myelination. ${ }^{20}$ In brief, the gut microbiota directly affects the development and healthy functioning of the mammalian brain. ${ }^{14}$

The leading evidence consolidating this view is that the gut microbiota composition of patients with depression is different from that of healthy individuals. The microbiota of patients with depression exhibits low-diversity dysbiosis. ${ }^{21}$ For example, the levels of Lactobacillus, Bifidobacterium, Firmicutes, Faecalibacterium and Ruminococcus decrease, while the levels of Provotella, Bacteroides and Proteobacteria increase. ${ }^{22,23}$ Results similar to human studies have been obtained in animal studies. ${ }^{24,25}$ However, consistent results cannot be obtained due to the methodological differences between the studies, and the validity of the findings continues to be discussed. ${ }^{26,27}$

If depression patients have a specific gut microbiota composition and if this bacterial content causes depression, it should lead to the formation of depression symptoms in healthy individuals when transplanted. In order to test this hypothesis, two studies with similar design that were conducted in two centers independent of each other were published in 2016. ${ }^{27,28}$ The feces of depression patients (depression microbiota) was transplanted to microbiota-deficient rats in the study by Kelly et al., and to germ-free (born by caesarean section and grown under sterile conditions) mice in the study by Zheng et al. In both experiments, depressive symptoms and metabolic changes were determined in the experimental animals following fecal microbiota transplantation (FMT). ${ }^{27,28}$ According to the results of these studies, it can be speculated that dysbiosis may play a causal role for depression-like behaviors.

The incidence of depression has significantly increased in the last few decades. ${ }^{29}$ One of the leading causes for this may be the global increase in the use of antibiotics. ${ }^{30}$ Systemic antibiotics are used even for the treatment of local infections, such as tonsillitis, and these antibiotics also kill symbiotic bacteria in the gut microbiota. It is thought that the use of antibiotics causes dysbiosis, and therefore leads to neuropsychiatric disorders. ${ }^{31,32}$ In the studies with large sample sizes conducted in this respect, a significant correlation was found between the dose and duration of antibiotic use and the probability of neuropsychiatric disorder. ${ }^{30,33}$ Similarly, it was found that infants with antibiotic exposure within the first year after birth had higher rates of behavioral problems, depression symptoms and neurocognitive impairment in the later years of life. ${ }^{34}$ In the subsequent study conducted by the same research team on the same cohort, it was found that neurocognitive problems were continuing above the age of 11 years. ${ }^{35}$

One of the factors affecting the gut microbiota is diet. ${ }^{36,37} \mathrm{~A}$ great deal of evidence suggesting that unhealthy (fast-food and western-type) diet destroys the gut bacterial composition, reduces the bacterial diversity and richness, and predisposes to depression by causing dysbiosis have been obtained. ${ }^{38-40}$

In conclusion, depression can be defined as a multifactorial disease in which neuronal, hormonal, nutritional, antimicrobial and microbiotal factors play a complex and combined role in the etiopathogenesis.

\section{NEUROINFLAMMATION IN DEPRESSION}

Neuroinflammation is a condition which involves the activation of nerve cells in the central nervous system and in which changes similar to neural degeneration are observed. The four cardinal signs, calor (heat), dolor (pain), rubor (redness) and tumor (swelling), in the classical inflammation definition by Roman Celsus are not seen in neuroinflammation. By increasing pro-inflammatory cytokines through the changes in the HPA axis and neurotransmitter synthesis, inflammation creates a kind of allostatic load, including the endocrine and nervous system. ${ }^{41}$ 
Numerous research data indicate that immune dysregulation and chronic inflammation play a role in the onset and persistence of depression, resistance to treatment, and relapse. ${ }^{42-45} \mathrm{As}$ a result of increased cytokines due to both peripheral chronic inflammation and central microglia stimulation, depressive symptoms may show up. Peripheral stimuli such as inflammation, chronic stress and infection may trigger the activation of microglia in the brain, resulting in release of pro-inflammatory cytokines ${ }^{46}$ Depressive symptoms are also seen in physical diseases such as cancer, autoimmune diseases or systemic infections in which chronic inflammation has been implicated. ${ }^{47}$

Being filtered from the leaky areas in the blood-brain barrier through active transport, the pro-inflammatory cytokines in the periphery act on the brain by the activation of endothelial cells and perivascular macrophages in the cerebral vascular walls and binding to the cytokine receptors associated with peripheral nerve fibers such as the vagus nerve. ${ }^{47}$

Depression is frequently triggered by stress, and stress activates the immune system through the HPA axis. Psychosocial problems, sleep disorder, poor diet, insufficient physical activity and environmental stresses such as smoking activate lowgrade inflammatory and oxidative stress pathways. ${ }^{48,49}$ In some cases of depression, there is an increase in the oxidation products that damage lipids, proteins and nucleic acids as a result of oxidative and nitrosative stress. ${ }^{49}$ The fact that depression frequently coexists in pro-inflammatory conditions such as obesity, myocardial infarction and autoimmune diseases is consistent with this. ${ }^{50,51}$

Increased cytokines cause disorders in the serotonergic and noradrenergic circuitries by activating the HPA axis, or depletion of serotonin with the increased activity of the indoleamine2,3-deoxygenase (IDO) enzyme in the tryptophan/kynurenine system. ${ }^{52,53}$ In some of depression cases, the levels of proinflammatory cytokine in peripheral blood, such as IL-1 beta, IL-6, IL-18, interferon-gamma (INF- $\gamma$ ), sIL-2R and CRP (an acute phase protein and inflammatory marker) have been shown to increase. ${ }^{53-58}$ The levels of cytokine and CRP also improve in patients whose depression improves..$^{59}$

Another factor that increases the pro-inflammatory cytokine concentrations is leaky gut, which develops as a result of interaction with gut microbes. ${ }^{60}$ According to the leaky gut theory, it has been suggested that microglia contributes to the production of peripheral and central pro-inflammatory cytokines in some of depressive cases Intestinal microorganisms may cause changes in neurotransmitter levels by affecting the tryptophan metabolism. ${ }^{61}$ It was reported that the levels of IgM and Ig A produced against lipopolysaccharides (LPS) of enterobacteria were higher in depressive cases than in controls. Increased levels of IgM and IgA indicate that intestinal permeability is increased, and thus, invasive enterobacteria cause sys- temic and central inflammation. ${ }^{39,62}$ In an animal study, the blockage of the peripheral IL- 6 receptor by the anti-mouse IL-6 antibody has been shown to lead to a rapid and permanent antidepressant effect by normalizing the altered composition of gut microbiology. ${ }^{63}$

In a 1991 paper by Smith, one of the first papers on the association between inflammation and depression, it was argued that the "food-gut-allergy axis" may play a role in macrophage activation In this study, it was observed that especially dairy products could cause behavioral dysfunction, and fish oil was recommended for the prophylaxis of depression. ${ }^{54}$

In summary, neuroinflammation plays a role in the pathophysiology of depression by increasing proinflammatory cytokines, activating the HPA axis, increasing the glucocorticoid resistance, affecting the synthesis and metabolism of serotoninnorepinephrin-dopamine, increasing neuronal apoptosis and negatively affecting neurogenesis and neuroplasticity.

\section{EFFICACY OF MICROBIOTA RESTORATION IN DEPRESSION}

Mental and physiological diseases associated with dysbiosis in gut microbiota can be reversed by restoration of dysbiosis. ${ }^{64,65}$ Microbiota can be restored by prebiotics, probiotics and $\mathrm{FMT}^{66}$ Besides that, the importance of healthy diet is undeniable ${ }^{67}$ Because our foods are also the nutrients of bacteria in the gut microbiota. ${ }^{66}$ These healthy foods, which are also the nutrients of beneficial bacteria in the gut, are called "prebiotics". ${ }^{68}$ Omega-3 fatty acids, fructose-oligosaccharide, and galacto-oligosaccharide are the prebiotics that have been shown to have positive efficacy in the gut-brain axis. ${ }^{68}$ Moreover, some microbiota bacteria (Bacteroides fragilis and Faecalibacterium prausnitzii) provide the production of short-chain fatty acids (acetate, butyrate and propionate) from fiber. These fatty acids get mixed into the systemic circulation and show antiinflammatory activity ${ }^{69}$

The term "probiotic" is defined as living microorganisms that produce positive effects on host's health. ${ }^{66}$ Probiotic bacteria were termed as "psychobiotics" by Dinan et al..$^{70}$ due to the improvements in neuronal functions further to their benefits on overall body health, and presented as "novel class of psychobiotics". The positive effects of probiotics in the treatment of depression were first reported in the literature by Phillips's paper in $1910 .{ }^{71}$ Probiotic microorganisms have been studied in a number of clinical and preclinical randomized controlled trials by being comparing with antidepressants. ${ }^{72,73}$ In the light of these studies, bacteria such as Bifidobacterium bifidum, Lactobacillus helveticus and Lactobacillus casei have been classified as psychobiotics since they exhibit anxiolytic and antidepressant characteristics. ${ }^{74-76}$ 
Perhaps the most dramatic and drastic way to restore dysbiosis is FMT. FMT is the transplantation of feces taken from a healthy donor to the intestines of the patient in order to restore dysbiosis. ${ }^{77}$ The primary area of usage of FMT is inflammatory bowel diseases such as ulcerative colitis and Crohn's disease. In our previous review, the potential use of FMT in neuropsychiatric indications was discussed. ${ }^{66}$ This preliminary paper in the literature is an important reference for FMT studies in the field of neuropsychiatry, which are still at the crawling stage. In a recent study we conducted in this field, the severities of anxiety, depression and obsession were found to decline after the FMT procedure in inflammatory bowel patients. ${ }^{78}$ FMT may be an alternative treatment option, especially in patients resistant to traditional treatment methods. ${ }^{77}$

\section{ANTIMICROBIAL EFFECT OF CONVENTIONAL ANTIDEPRESSANTS}

The synaptic effect of antidepressants is well known. ${ }^{9,79}$ However, in recent years, it is thought that antidepressants not only have an effect on neurotransmitter systems, but also regulate the gut-brain axis by altering gut microbiota. The primary function of antidepressants leading to this effect is the mechanism of antimicrobial action. ${ }^{80}$ The first antidepressant inducing monoamine oxidase inhibition (MAO-I) is iproniazid, an antituberculosis drug. ${ }^{80}$ Over the years, it has been clarified that MAO-I antidepressants inhibit bacterial cell wall synthesis. In addition, selective serotonin reuptake inhibitor (SSRI) drugs inhibit the efflux pump, while tricyclic antidepressants (TCAs) exhibit an antibiotic effect by inhibiting both antiplasmid and DNA gyrase. Ketamine also exhibits an antimicrobial effect on Enterococcus, Staphylococcus and Candida albicans by acting as other antidepressants. In contrast, antibiotics such as minocycline and ceftriaxon also have antidepressive effects. ${ }^{80}$ Standard antidepressive efficacy is probably not only limited to synaptic functions, but is also obtained by regulation and restoration of gut microbiota. In this respect, FMT comes to the fore as a treatment option in treatment-resistant psychiatric disorders. ${ }^{77}$

\section{FUTURE PROJECTIONS}

With the better understanding of the role of dysbiosis in the etiopathogenesis of depression, new treatment approaches have acquired currency. For example, in a recent study, probiotics (Lactobacillus acidophilus, Bifidobacterium bifidum, Streptococcus thermophilus) and magnesium orotate (1,600 $\mathrm{mg} /$ day) were started to be administered to treatment-resistant despression patients $(\mathrm{n}=12)$ in addition to the SSRIs they were currently receiving. In the eighth week of the administra- tion, there was a statistically significant decrease in depression scores and an increase in the quality of life. The interesting result of the study is that relapse was observed in the $16 \mathrm{~h}$ week, although the patients continued to use SSRIs following the discontinuation of probiotic and magnesium orotate supplement. ${ }^{81}$ The most significant weakness of this study is the small sample size. In a recent meta-analysis study, the results of 10 studies $(n=1,349)$ were analyzed, and it was found that probiotic supplement had no significant therapeutic effect on mood. ${ }^{82}$

There is numerous evidence that the microbiota composition in patients with depression is impaired due to various reasons (antibiotic use, unhealthy diet, stress, genetic causes, city life, etc.). Besides the publications arguing that microbiotabased or as we propose, "fecomodulation" treatments (psychobiotic, prebiotic and FMT) have antidepressive effect in order to restore dysbiosis, there are also studies demonstrating that they are ineffective. ${ }^{14}$ In order to clarify the contradictory results, there is a need for studies investigating immunological, endocrine and metabolic parameters, as well as microbiota composition analyses to be conducted on large samples.

\section{CONCLUSION}

In the past 70 years, very important scientific developments and discoveries were achieved for the etiopathogenesis and treatment of depression. Effective and reliable antidepressant drugs have been put into use with the advancement of the monoamine hypothesis and modern psychopharmacology. However, the success rates of antidepressants are not satisfactory due to delay in treatment efficacy, inadequacy in remission rates and side effects that may prevent the continuation of the treatment (weight gain, sexual dysfunction, sedation, etc.).

The microbiota hypothesis, which is an alternative to the monoamine hypothesis, argues that the main problem in the etiopathogenesis of depression is dysbiosis. Low-grade inflammation occurs due to leaky gut and endotoxemia arising on the basis of dysbiosis. Neuroinflammation occurs as a reflection of systemic inflammation. The problems in the monoaminergic system are the result of neuroinflammation. Conventional antidepressants not only have an effect on the levels of neurotransmitters in the synaptic gap, but also fix dysbiosis. Using the fecomodulation treatments, the source of the problem is intervened in the treatment of depression. Among these treatments, FMT provides the most dramatic and drastic effect.

Although the first study on the use of probiotics in the treatment of depression was published in 1910, the interest of the current science in the issue has increased after the 2005 paper by Logan and Katzman. Both animal experiments and randomized controlled clinical trials suggest that probiotics are effective in the treatment of depression. However, obtaining 
conflicting results makes it difficult to reach a definitive conclusion. There are only a few clinical studies on the use of FMT in neuropsychiatric indications.

In conclusion, there is promising evidence for the use of fecomodulation treatments in neuropsychiatric indications, especially depression. The significance of fecomodulation treatments, which aim to fix dysbiosis in the treatment and prophylaxis of depression, appears to increase in the near future.

\section{Conflicts of Interest}

The authors have no potential conflicts of interest to disclose.

\section{Author Contributions}

Conceptualization: All authors. Data curation: Alper Evrensel, Barış Önen Ünsalver. Formal analysis: Alper Evrensel, Barıș Önen Ünsalver. Investigation: Alper Evrensel, Barış Önen Ünsalver. Methodology: All authors. Project administration: Alper Evrensel. Resources: Alper Evrensel, Barış Önen Ünsalver. Software: All authors. Supervision: Mehmet Emin Ceylan. Validation: All authors. Visualization: All authors. Writing_-original draft: Alper Evrensel, Barış Önen Ünsalver. Writing_-review \& editing: All authors.

\section{ORCID iDs}

Alper Evrensel https://orcid.org/0000-0001-7037-0240

\section{REFERENCES}

1. Gerhard DM, Wohleb ES, Duman RS. Emerging treatment mechanisms for depression: focus on glutamate and synaptic plasticity. Drug Discov Today 2016;21:454-464.

2. Ledford H. Medical research: if depression were cancer. Nature 2014; 515:182-184.

3. Smith K. Mental health: a world of depression. Nature 2014; 515:181.

4. Belmaker RH, Agam G. Major depression disorder. N Engl J Med 2008; 358:55-68.

5. Corfield EC, Yang Y, Martin NG, Nyholt DR. A continuum of genetic liability for minor and major depression. Transl Psychiatry 2017;7:e1131.

6. Bukh JD, Bock C, Vinberg, M, Werge T, Gether U, Vedel Kessing L. Interaction between genetic polymorphisms and stressful life events in first episode depression. J Affect Disord 2009;119: 107-115.

7. Evrensel A, Ceylan ME. The gut-brain axis: the missing link in depression. Clin Psychopharmacol Neurosci 2015;13:239-244.

8. Evrensel A, Ünsalver BÖ, Ceylan ME. Psychobiotics. In: Kim YK, Editor. Frontiers in Psychiatry. Advances in Experimental Medicine and Biology, vol 1192. Singapore: Springer, 2019, p.565-581.

9. Stahl SM. Stahl's Essential Psychopharmacology: Neuroscientific Basis and Practical Applications. 4th Ed. New York: Cambridge University Press; 2013.

10. Pytka K, Dziubina A, Mlyniec K, Dziedziczak A, Zmudzka E, Furgala $A$, et al. The role of glutamatergic, gaba-ergic, and cholinergic receptors in depression and antidepressant-like effect. Pharmacol Rep 2016;68: 443-450.

11. Liu B, Liu J, Wang M, Zhang Y, Li L. From serotonin to neuroplasticity: evolvement of theories for major depressive disorder. Front Cell Neurosci 2017;11:305.

12. Barden N. Implication of the hypothalamic-pituitary-adrenal axis in the physiopathology of depression. J Psychiatry Neurosci 2004;29:185-193.

13. Juruena MF, Cleare AJ, Pariante CM. The hypothalamic pituitary adrenal axis, glucocorticoid receptor function and relevance to depression. Braz J Psychiatry 2004;26:189-201.

14. Evrensel A, Önen Ünsalver B, Ceylan ME. Therapeutic potential of the microbiome in the treatment of neuropsychiatric disorders. Med Sci (Basel) 2019;7:21
15. Seferovic MD, Pace RM, Caroll M, Belfort B, Major AM, Chu DM, et al. Visualization of microbes by $16 \mathrm{~s}$ in situ hybridization in term and preterm placentae without intraamniotic infection. Am J Obstet Gynecol 2019;221:146.e1-146.e23.

16. Honda K, Littma DR. The microbiota in adaptive immune homeostasis and disease. Nature 2016;535:75-84.

17. Sudo N. Microbiome, HPA axis and production of endocrine hormones in the gut. Adv Exp Med Biol 2014;817:177-194.

18. Bien-Ly N, Watts RJ. The blood-brain barrier's gut check. Sci Transl Med 2014;6:263fs46.

19. Ogbonnaya ES, Clarke G, Shanahan F, Dinan TG, Cryan JF, O'leary OF. Adult hippocampal neurogenesis is regulated by the microbiome. Biol Psychiatry 2015;78:e7-e9.

20. Hoban AE, Stilling RM, Ryan FJ, Shanahan F, Dinan TG, Claesson MJ, et al. Regulation of prefrontal cortex myelination by the microbiota. Transl Psychiatry 2016;6:e774.

21. Jiang H, Ling Z, Zhang Y, Mao H, Ma Z, Yin Y, et al. Altered fecal microbiota composition in patients with major depressive disorder. Brain Behav Immun 2015;48:186-194.

22. Liu Y, Zhang L, Wang X, Wang Z, Zhang J, Jiang R, et al. Similar fecal microbiota signatures in patients with diarrhea-predominant irritable bowel syndrome and patients with depression. Clin Gastroenterol Hepatol 2016;14:1602-1611.

23. Aizawa E, Tsuji H, Asahara T, Takahashi T, Teraishi T, Yoshida S, et al. Possible association of bifidobacterium and lactobacillus in the gut $\mathrm{mi}$ crobiota of patients with major depressive disorder. J Affect Disord 2016; 202:254-257.

24. Park AJ, Collins J, Blennerhassett PA, Ghia JE, Verdu EF, Bercik P, et al. Altered colonic function and microbiota profile in a mouse model of chronic depression. Neurogastroenterol Motil 2013;25:733-e575.

25. Yu M, Jia H, Zhou C, Yang Y, Zhao Y, Yang M, et al. Variations in gut microbiota and fecal metabolic phenotype associated with depression by $16 \mathrm{~S}$ rRNA gene sequencing and LC/MS-based metabolomics. J Pharm Biomed Anal 2017;138:231-239.

26. Lin P, Ding B, Feng C, Yin S, Zhang T, Qi X, et al. Prevotella and Klebsiella proportions in fecal microbial communities are potential characteristic parameters for patients with major depressive disorder. J Affect Disord 2017;207:300-304.

27. Zheng P, Zeng B, Zhou C, Liu M, Fang Z, Xu X, et al. Gut microbiome remodeling induces depressive-like behaviors through a pathway mediated by the host's metabolism. Mol Psychiatry 2016;21:786-796.

28. Kelly JR, Borre Y, O’brien C, Patterson E, El Aidy S, Deane J, et al. Transferring the blues: Depression-associated gut microbiota induces neurobehavioural changes in the rat. J Psychiatr Res 2016;82:109-118.

29. GBD 2016 DALYs and HALE Collaborators. Global, regional, and national disability-adjusted life-years (DALYs) for 333 diseases and injuries and healthy life expectancy (HALE) for 195 countries and territories, 1990-2016: a systematic analysis for the Global Burden of Disease Study 2016. Lancet 2017;390:1260-1344.

30. Lurie I, Yang YX, Haynes K, Mamtani R, Boursi B. Antibiotic exposure and the risk for depression, anxiety, or psychosis: a nested case-control study. J Clin Psychiatry 2015;76:1522-1528.

31. Frohlich EE; Farzi A, Mayerhofer R, Reichmann F, Jacan A, Wagner B, et al. Cognitive impairment by antibiotic-Induced gut dysbiosis: analysis of gut microbiota-brain communication. Brain Behav Immun 2016; 56:140-155.

32. Bercik P, Collins SM. The effects of inflammation, infection and antibiotics on the microbiota-gut-brain axis. Adv Exp Med Biol 2014;817:279289.

33. Kohler O, Petersen L, Mors O, Mortensen PB, Yolken RH, Gasse C, et al. Infections and exposure to anti-nfective agents and the risk of severe mental disorders: A nationwide study. Acta Psychiatr Scand 2017;135: 97-105.

34. Slykerman RF, Thompson J, Waldie KE, Murphy R, Wall C, Mitchell EA. Antibiotics in the first year of life and subsequent neurocognitive 
outcomes. Acta Paediatr 2017;106:87-94.

35. Slykerman RF, Coomarasamy C, Wickens K, Thompson JMD, Stanley TV, Barthow C, et al. Exposure to antibiotics in the first 24 months of life and neurocognitive outcomes at 11 years of age. Psychopharmacology (Berl) 2019;236:1573-1582.

36. Bereswill S, Pyndt Jørgensen B, Hansen JT, Krych L, Larsen C, Klein $\mathrm{AB}$, et al. A possible link between food and mood: dietary impact on gut microbiota and behavior in BALB/c mice. PLoS One 2014;9:e103398.

37. Oriach CS, Robertson RC, Stanton C, Cryan JF, Dinan TG. Food for thought: the role of nutrition in the microbiota-gut-brain axis. Clin Nutr Exp 2016;6:25-38.

38. Owen L, Corfe B. The role of diet and nutrition on mental health and wellbeing. Proc Nutr Soc 2017;76:425-426.

39. Slyepchenko A, Maes M, Jacka FN, Köhler CA, Barichello T, McIntyre RS, et al. Gut microbiota, bacterial translocation, and interactions with diet: pathophysiological links between major depressive disorder and non-communicable medical comorbidities. Psychother Psychosom 2017;86:31-46.

40. Noble EE, Hsu TM, Kanoski SE. Gut to brain dysbiosis: mechanisms linking western diet consumption, the microbiome, and cognitive impairment. Front Behav Neurosci 2017;1:9.

41. Jeon SW, Kim YK. The role of neuroinflammation and neurovascular dysfunction in major depressive disorder. J Inflamm Res 2018:11:179192.

42. Carvalho LA, Torre JP, Papadopoulos AS, Poon L, Juruena MF, Markopoulou $\mathrm{K}$, et al. Lack of clinical therapeutic benefit of antidepressants is associated overall activation of the inflammatory system. J Affect Disord 2013;148:136-140.

43. Kiecolt-Glaser JK, Derry HM, Fagundes CP. Inflammation: depression fans the flames and feasts on the heat. Am J Psychiatry 2015;172:10751091.

44. Miller AH, Raison CL. The role of inflammation in depression: from evolutionary imperative to modern treatment target. Nat Rev Immunol 2016;16:22-34.

45. Woelfer M, Kasties V, Kahlfuss S, Walter M. The role of depressive subtypes within the neuroinflammation hypothesis of major depressive disorder. Neuroscience 2019;403:93-110.

46. Song C, Wang H. Cytokines mediated inflammation and decreased neurogenesis in animal models of depression. Prog Neuropsychopharmacol Biol Psychiatry 2011;35:760-768.

47. Dantzer R, O'Connor JC, Freund GG, Johnson RW, Kelley KW. From inflammation to sickness and depression: when the immune system subjugates the brain. Nat Rev Neurosci 2008;9:46-56.

48. Berk M, Williams LJ, Jacka FN, O’Neil A, Pasco JA, Moylan S, et al. So depression is an inflammatory disease, but where does the inflammation come from? BMC Med 2013;11:200.

49. Moylan S, Berk M, Dean OM, Samuni Y, Williams LJ, O’Neil A, et al. Oxidative and nitrosative stress in depression: why so much stress? Neurosci Biobehav Rev 2014;45:46-62.

50. Shelton RC, Miller AH. Eating ourselves to death (and despair): the contribution of adiposity and in ammation to depression. Prog Neurobiol 2010;91:275-299.

51. Raison CL. Inflammatory depression: a trifecta of trouble. J Clin Psychiatry 2014;75:663-664.

52. Kopschina Feltes P, Doorduin J, Klein HC, Juárez-Orozco LE, Dierckx RA, Moriguchi-Jeckel CM, et al. Anti-inflammatory treatment for major depressive disorder: implications for patients with an elevated immune profile and non-responders to standard antidepressant therapy. J Psychopharmacol 2017;31:1149-1165.

53. Dowlati Y, Herrmann N, Swardfager W, Liu H, Sham L, Reim EK, et al. A meta- analysis of cytokines in major depression. Biol Psychiatry 2010; 67:446-457.

54. Smith RS. The macrophage theory of depression. Med Hypotheses 1991; 35:298-306.

55. Liu Y, Ho RC, Mak A. Interleukin (IL)-6, tumour necrosis factor alpha
(TNF- $\alpha$ ) and soluble interleukin-2 receptors (sIL-2R) are elevated in patients with major depressive dis- order: a meta-analysis and meta-regression. J Affect Disord 2012;139:230-239.

56. Sukoff Rizzo SJ, Neal SJ, Hughes ZA, Beyna M, Rosenzweig-Lipson S, Moss SJ, et al. Evidence for sustained elevation of IL-6 in the CNS as a key contributor of depressive-like phenotypes. Transl Psychiatry 2012;2: e199.

57. Rawdin B, Mellon S, Dhabhar F, Epel ES, Puterman E, Su Y, et al. Dysregulated relationship of inflammation and oxidative stress in major depression. Brain Behav Immun 2013; 31:143-152.

58. Krogh J, Benros ME, Jørgensen MB, Vesterager L, Elfving B, Nordentoft $M$. The association between depressive symptoms, cognitive function, and inflammation in major depression. Brain Behav Immun 2014; 35:70-76.

59. Lanquillon S, Krieg JC, Bening-Abu-Shach U, Vedder H. Cytokine production and treatment response in major depressive disorder. Neuropsychopharmacol 2000;22:370-379.

60. O'Brien SM, Scott LV, Dinan TG. Cytokines: abnormalities in major depression and implications for pharmacological treatment. Hum Psychopharmacol 2004;19:397-403.

61. Agus A, Planchais J, Sokol H. Gut microbiota regulation of tryptophan metabolism in health and disease. Cell Host Microbe 2018;23:716-724.

62. Maes M, Kubera M, Leunis JC. The gut-brain barrier in major depression: intestinal mucosal dysfunction with an increased translocation of LPS from gram negative enterobacteria (leaky gut) plays a role in the inflammatory pathophysiology of depression. Neuro Endocrinol Lett 2008;29:117-124.

63. Zhang JC, Yao W, Dong C, Yang C, Ren Q, Ma M. Blockade of interleukin- 6 receptor in the periphery promotes rapid and sustained antidepressant actions: a possible role of gut-microbiota-brain axis. Transl Psychiatry 2017;7:e1138.

64. Rieder R, Wisniewski PJ, Alderman BL, Campbell SC. Microbes and mental health: a review. Brain Behav Immun 2017;66:9-17.

65. Grenham S, Clarke G, Cryan JF, Dinan, TG. Brain-gut-microbe communication in health and disease. Front Physiol 2011;2:94.

66. Evrensel A, Ceylan ME. Fecal microbiota transplantation and its usage in neuropsychiatric disorders. Clin Psychopharmacol Neurosci 2016;14: 231-237.

67. Sandhu KV, Sherwin E, Schellekens H, Stanton C, Dinan TG, Cryan JF. Feeding the microbiota-gut-brain axis: Diet, microbiome, and neuropsychiatry. Transl Res 2017;179:223-244.

68. Gibson GR, Hutkins R, Sanders ME, Prescott SL, Reimer RA, Salminen SJ, et al. Expert consensus document: The International Scientific Association For Probiotics And Prebiotics (ISAPP) consensus statement on the definition and scope of prebiotics. Nat Rev Gastroenterol Hepatol 2017;14:491-502.

69. Bollrath J, Powrie F. Immunology. Feed your Tregs more fiber. Science 2013;341:463-464.

70. Dinan TG, Stanton C, Cryan JF. Psychobiotics: A novel class of psychotropic. Biol Psychiatry 2013;74:720-726.

71. Phillips JGP. The treatment of melancholia by the lactic acid bacillus. $\mathrm{Br}$ J Psychiatry 1910;56:422-431.

72. Pirbaglou M, Katz J, De Souza RJ, Stearns, JC, Motamed M, Ritvo P. Probiotic supplementation can positively affect anxiety and depressive symptoms: a systematic review of randomized controlled trials. Nutr Res 2016;36:889-898.

73. Wallace CJK, Milev R. The effects of probiotics on depressive symptoms in humans: A systematic review. Ann Gen Psychiatry 2017;16:14.

74. Liang S, Wang T, Hu X, Luo J, Li W, Wu X, et al. Administration of Lactobacillus helveticus NS8 improves behavioral, cognitive, and biochemical aberrations caused by chronic restraint stress. Neuroscience. 2015; 310:561-577.

75. Akkasheh G, Kashani-Poor Z, Tajabadi-Ebrahimi M, Jafari P, Akbari H, Taghizadeh $\mathrm{M}$, et al. Clinical and metabolic response to probiotic administration in patients with major depressive disorder: A randomized, 
double-blind, placebo-controlled trial. Nutrition 2016;32:315-320.

76. Abildgaard A, Elfving B, Hokland M, Wegener G, Lund S. Probiotic treatment reduces depressive-like behaviour in rats independently of diet. Psychoneuroendocrinology 2017;79:40-48.

77. Evrensel A, Ceylan ME. Fecal Microbiota Transplantation in the Treatment-Resistant Psychiatric Disorders. In: Kim YK, Editor. Treatment Resistance in Psychiatry. Singapore: Springer, 2019, p.369-376.

78. Evrensel A, Kilıçaslan S. The effect of fecal microbiota transplantation on psychiatric symptoms among patients with inflammatory bowel disease: an experimental study. Actas Esp Psiquiatr 2019 [Epub ahead of print]

79. Stahl SM. Beyond the dopamine hypothesis of schizophrenia to three neural networks of psychosis: dopamine, serotonin, and glutamate. CNS
Spectrums 2018;23:187-191.

80. Macedo D, Filho A, Soares De Sousa CN, Quevedo J, Barichello T, Junior HVN, et al. Antidepressants, antimicrobials or both? Gut microbiota dysbiosis in depression and possible implications of the antimicrobial effects of antidepressant drugs for antidepressant effectiveness. J Affect Disord 2017;208:22-32.

81. Bambling M, Edwards SC, Hall S, Vitetta LA. Combination of probiotics and magnesium orotate attenuate depression in a small SSRI resistant cohort: an intestinal anti-inflammatory response is suggested. Inflammopharmacology 2017;25:271-274.

82. Ng QX, Peters C, Ho CYX, Lim DY, Yeo WS. A meta-analysis of the use of probiotics to alleviate depressive symptoms. J Affect Disord 2018;228: 13-19. 